\title{
Economía y libertad. Diálogo entre Adolfo Sánchez Vázquez y Eduardo Nicol
}

\author{
Economy and Freedom. \\ Dialogue between Adolfo Sánchez Vázquez. \\ and Eduardo Nicol
}

\author{
IVER A. BELTRÁN G. \\ Universidad de Chalcatongo (Oaxaca, México)
}

Recibido: 06/04/16 Aceptado: 22/11/16

\begin{abstract}
RESUMEN
Hacemos la exégesis mínima de una crítica de Sánchez Vázquez a Nicol. Conforme a tal crítica, en la filosofía de éste hay una separación entre el ser del hombre y su base económica. Nuestro planteamiento es que tal crítica manifiesta una diferencia de énfasis y no una discrepancia de fondo, pues ambos filósofos rechazan un determinismo económico fuerte, aunque aceptan que la economía es condición necesaria para las otras estructuras sociales, además de que uno y otro comparten la idea de que el hombre produce su propio ser a través de la creación de necesidades propiamente humanas.
\end{abstract}

PALABRAS CLAVE

PRAXIS, DETERMINISMO ECONÓMICO, RACIONALIDAD, HISTORIA

\begin{abstract}
We explain the meaning of a Sánchez Vázquez's criticism about Nicol, namely, that the philosophy of the latter separates the being of man and his economic base. In accordance with our approach, this criticism expresses a difference of emphasis, not a fundamental disagreement, on

(C) Contrastes. Revista Internacional de Filosofía, vol. XXII-N² (2017), pp. 23-38. ISSN: 1136-4076

Departamento de Filosofía, Universidad de Málaga, Facultad de Filosofía y Letras Campus de Teatinos, E-29071 Málaga (España)
\end{abstract}


the grounds that both philosophers reject the strong economic determinism but instead accept that economy is a necessary condition for the other social structures, and because both Nicol and Sánchez Vázquez agree with the idea that man produces his own being through the creation of distinctive human needs.

KEY WORDS

PRAXIS, ECONOMIC DETERMINISM, RATIONALITY, HISTORY

\section{INTRODUCCIÓN}

En 1989, durante un homenaje a Eduardo Nicol (Barcelona, 1907-1990), Adolfo Sánchez Vázquez (Algeciras, Cádiz, 1915-2011) pronuncia un discurso en el que reconoce a Nicol y a David García Bacca como excepciones entre los filósofos del exilio republicano español por haber establecido durante el exilio un contacto significativo con la obra de Marx. De Nicol, específicamente, destaca que supo distinguir el núcleo vivo de la filosofía de Marx en una época en la que predominaba un marxismo dogmático. Al final del discurso, Sánchez Vázquez efectúa una observación crítica al pensamiento de Eduardo Nicol:

[...] no obstante los logros alcanzados en su intento de vincular esencia y fenómeno, verdad e historia, filosofía y situación vital, hombre e historia, hay todavía en el pensamiento de Nicol - particularmente al examinar la enajenación o la crisis del hombre - una carga especulativa puesta en él por cierto antropologismo no superado al tratar de poner en relación al hombre con la historia, la praxis y la vida real. Y esta carga especulativa se hace notar al examinar el hombre que se enajena, se mecaniza o está en crisis en la sociedad actual. Podríamos decir que al separar a ese hombre de la crisis del sistema económico y social en que se inserta, no obstante el loable intento de poner en relación hombre e historia, Nicol no escapa por completo al reproche que él mismo ha hecho, en Historicismo y existencialismo, a Heidegger: proclamar la historicidad del hombre sin atender a su historia real (Sánchez Vázquez 1997, 193).

Muy pocas líneas, pero densas. Pues bien, junto con la comprensión mínima indispensable del contexto teórico implícito, en el presente trabajo nos proponemos mostrar que la crítica de Sánchez Vázquez no implica una discrepancia de fondo entre ambos filósofos respecto al lugar de la economía entre las estructuras de la sociedad, sino que se refiere a una diferencia de énfasis.

Sánchez Vázquez y Nicol no desarrollaron en su momento un diálogo efectivo. Por ello, tomamos como punto de partida y como referencia recurrente la observación crítica de Sánchez Vázquez. Nuestro método consiste en tomar como base sus textos, confiriendo a nuestra lectura una trayectoria que trasciende esos 
textos, en el sentido de que busca el desenvolvimiento del potencial dialógico que las ideas de uno - por su mismo contraste - contienen respecto a las del otro.

Para comprender la crítica de Sánchez Vázquez es menester indicar el significado que para éste tienen el antropologismo y la especulación, de lo cual nos ocupamos en la sección II. En la sección III nos internamos en las ideas de Nicol sobre la crisis de nuestro tiempo, para aclarar cómo es que Sánchez Vázquez ve el antropologismo y una carga especulativa en esas ideas. Contando ya con una comprensión mínima del significado de la crítica de Sánchez Vázquez a Nicol, desarrollamos en la sección IV nuestra propuesta central.

Propuesta que se plantea en la perspectiva del diálogo y la comprensión entre las comunidades que Nicol y Sánchez Vázquez promovieron en el ámbito de la filosofía hispánica y que hoy en día conservan su dinamismo y fecundidad.

\section{EL «ANTROPOLOGISMO» Y LA «CARGA ESPECULATIVA» en la CRítica de SÁnCHEZ VÁzquez a Nicol}

En la observación crítica que tomamos como punto de partida, Sánchez Vázquez destaca en Nicol el «intento de vincular esencia y fenómeno, verdad e historia, filosofía y situación vital, hombre e historia», y en ese intento observa «una carga especulativa» que se explica por «cierto antropologismo» (Sánchez Vázquez 1997, p. 193). Pues bien, ¿qué entiende Sánchez Vázquez por antropologismo y por «carga especulativa», y qué relación establece entre ésta y aquél?

Este filósofo menciona el antropologismo en su principal obra, Filosofía de la praxis, cuando se refiere a los planteamientos de Feuerbach sobre la religión y el idealismo, y a los Manuscritos económico-filosóficos de 1844 (cfr. FP, pp. 139, 165, 167, 205). ${ }^{1}$

Sánchez Vázquez señala que Feuerbach representa un avance y, a la vez, un retroceso respecto a Hegel, pues éste, conforme a la lectura que Sánchez Vázquez realiza de la Fenomenología del espíritu y de la Ciencia de la Lógi$c a$, describe «aspectos importantes de la praxis real, efectiva, humana», pero hace de la misma «un momento del proceso de autoconciencia de lo absoluto», por lo cual esa praxis tiene, en última instancia, un carácter teórico: «sólo encuentra su fundamento, su verdadera naturaleza y su fin en el movimiento teórico mismo de lo Absoluto» (ibíd. pp. 101; cfr. ibíd. pp. 71-101). En cuanto a Feuerbach, la crítica que efectúa a la religión en La esencia del cristianismo plantea que no ha de entenderse al hombre como predicado de Dios sino a Dios como predicado del hombre, pues es el hombre quien crea a Dios y se objetiva en él, aunque después el hombre no reconozca a Dios como creación suya ( $c f r$.

1 Mediante al abreviatura «FP» nos referimos en adelante a Sánchez Vázquez 2003a. Para contextualizar la filosofía de la praxis de Sánchez Vázquez entre las corrientes históricas del marxismo, vid. Vargas Lozano 1995, pp. 267-282, y García Machado 2009. 
ibíd. pp. 102-103); tal crítica, señala Sánchez Vázquez, la extiende Feuerbach en otros escritos a la filosofía idealista de Hegel: «Así como en la religión se transfiere la esencia humana a Dios, la filosofía idealista, especulativa, transfiere la esencia del hombre y la naturaleza a la Idea Absoluta», la cual deviene sujeto, «mientras que el hombre y la naturaleza se reducen a predicados de la Idea» (ibíd. pp. 103-104). El avance de Feuerbach consiste, pues, en que «al ponerse como sujeto verdadero el hombre, y no el espíritu, se ha reducido el comportamiento teórico absoluto, que definía al Espíritu, a un comportamiento fundamentalmente teórico, pero humano» (ibíd. 126). El retroceso radica en el predominio que en la filosofía de Feuerbach tiene la teoría sobre la praxis, entre otras razones porque la liberación del hombre la opera, no la práctica, sino la teoría, al sustituir la falsa conciencia de la religión por una conciencia verdadera (cfr.ibíd.pp. 123-125). Hay pues un antropologismo en Feuerbach en tanto que, a pesar de comprender al hombre como un ser activo, creador, este filósofo no llega a ver la importancia que la actividad práctica tiene para el ser humano.

Sánchez Vázquez analiza en los escritos juveniles de Marx el proceso por el cual éste supera el predominio -identificado en Hegel y Feuerbach- de la teoría sobre la praxis (cfr.ibíd.pp. 127-208). Sin embargo, destaca también que en la Introducción a la Crítica de la filosofía del derecho, de Hegel (1843) y en los Manuscritos económico-filosóficos de 1844, Marx sigue preso de «cierto antropologismo feuerbachiano»: en la Introducción, debido a que su concepto del proletariado no avanza aún hacia su planteamiento «científico», objetivo, en términos de la estructura económica y social de la «sociedad burguesa» (FP, pp. 139-140); y en los Manuscritos..., porque presentan la esencia del hombre - ser que en su actividad material produce el mundo, sus relaciones con los otros hombres y a sí mismo - en tanto divorciada de su existencia como trabajador enajenado, como trabajador que no reconoce en sí mismo la fuente de todo aquello que produce ( $c f r$. FP, pp. 144, 165).

Vemos que el antropologismo de Feuerbach es asociado por Sánchez Vázquez al pensamiento especulativo, en cuanto este pensamiento no logra transitar a una concepción científica y objetiva del hombre, es decir, en la medida que no logra conceptualizar al ser del hombre a partir de su base económico-social. Si tomamos como referencia este análisis de las ideas de Feuerbach, podemos precisar que para Sánchez Vázquez el «antropologismo» consiste en elaborar una concepción del ser humano que separa a éste de sus condiciones materiales de existencia, y más precisamente, de su base económico-social; y que hay «carga especulativa» en el pensamiento cuando éste carece de la cientificidad y la objetividad necesarias para suprimir tal separación. Así, de acuerdo con este filósofo el intento de Nicol por vincular «esencia y fenómeno, verdad e historia, filosofía y situación vital, hombre e historia» es un intento sin éxito, un intento al que hace falta reunir al hombre que está en crisis en la sociedad actual y 
«la crisis del sistema económico y social en que se inserta» (Sánchez Vázquez 1997, p. 193); es decir, un intento que se dirige a describir el ser del hombre en toda su concreción y que sin embargo - conforme al planteamiento de Sánchez Vázquez-, resulta ser una descripción incompleta, abstracta.

Consideramos que, en sus puntos básicos, así puede ser válidamente interpretada la crítica de Sánchez Vázquez a Nicol. Ahora bien, aquél señala que la carga especulativa y el antropologismo de éste se hacen notar «al examinar el hombre que se enajena, se mecaniza o está en crisis en la sociedad actual», y que por ello Nicol llega de alguna forma a «proclamar la historicidad del hombre sin atender a su historia real» (Sánchez Vázquez 1997, p. 193). Por tanto, si queremos tener una comprensión suficiente de dicha crítica, hemos de internarnos en las ideas de Nicol relativas a la crisis de nuestro tiempo.

III. El OCASO DE LAS VOCACIONES LIBRES.

Nicol ante la CRítica de SÁnChez VÁZqueZ

En su metafísica, Nicol describe al hombre como un ser radicalmente histórico (cfr. Nicol 1974, pp. 153-157). ${ }^{2}$ Sin embargo, el cambio que afecta desde la raíz el ser del hombre, no es anárquico o caótico, posee su racionalidad, su orden: el ser del hombre está estructurado por situaciones vitales, que son las formas de relacionarse el hombre con todo lo que no es él. ${ }^{3}$ Entre las situaciones del hombre deben destacarse por su importancia para nuestro tema las situaciones fundamentales, que comparten todos los seres humanos por el solo hecho de ser humanos, ya siempre o desde un cierto momento en la historia (cfr. Nicol 1963, p. 110).

Entre las situaciones fundamentales cuenta Nicol los componentes del mundo, entendiendo al mundo en el sentido de un orden formado por el hombre con base en el orden dado del universo ( $c f r$. Nicol 1980, p. 125). Componentes fundamentales son la economía, la política y el derecho, que se enmarcan en una «praxis práctica», distinta de la «praxis impráctica». Mientras que «el dispositivo práctico sólo se puede adoptar respecto de la physis individual», en cambio «es existencialmente imposible, ante el ser y ante la physis universal, adoptar un dispositivo que no sea im-práctico» (Nicol 1978, p. 63). Es decir, el hombre se relaciona con lo que no es él en la «praxis práctica» adoptando como disposición el interés (búsqueda de provecho, utilidad, ganancia), y en la «praxis impráctica» el desinterés; como consecuencia, aquello que no es ese hombre particular (individuo o comunidad), lo otro de ese hombre, en la «praxis práctica» se fragmenta en una multiplicidad dispersa de entes, en cadenas de

2 Para la relación en la metafísica de Nicol entre la concepción del hombre y la concepción de la historia de la filosofía, vid. González, Roberto 2014.

3 Para el sentido del adjetivo «vital» en este contexto, vid. Nicol 1963, pp. 95-107. 
medios y fines; mientras que en la «praxis impráctica», contrariamente, se articula y reúne en una totalidad, o cosmos. Sólo hay tres dispositivos de «praxis impráctica», que han de ser entendidos también como componentes del mundo: «el teórico, el místico y el estético» (íd.), o ciencia, religión y arte. ${ }^{4}$

Estas situaciones fundamentales, componentes del mundo o dispositivos se refieren a la "praxis impráctica», y constituyen vocaciones en sentido estricto (cfr. Nicol 1974, pp. 242, 249-252). ${ }^{5}$ El individuo humano, que en el transcurso de la historia se diferencia respecto a su comunidad cuantitativamente, por grados, también se diferencia cualitativamente, por la disposición ante el ser que adopta de situación en situación o con preferencia sistemática en toda situación: «Descubrirse el hombre a sí mismo, y descubrir varias maneras de ponerse frente al ser, son una y la misma cosa» (ibíd. p. 250). Es decir que la forma que adopta el hombre para relacionarse con lo que no es él, con lo otro, implica una determinada forma de relacionarse el hombre consigo mismo, un desdoblamiento: la conciencia de sí o autoconciencia, por la cual cada hombre puede ser considerado obra de su propia acción. «La auto-conciencia es prueba existencial de la libertad» (Nicol 1977, p. 46).

Pues efectivamente, el hombre, en la metafísica de Nicol, es el ser de la libertad, aunque su acción no se explica sólo por la libertad. En la relación que el hombre adopta hacia lo otro, permanecen constantes los términos -lo humano, lo divino y la naturaleza-, así como los factores - la necesidad, la libertad y el azar (cfr. ibíd. pp. 17, 24). Que el hombre es un ser libre, lo ve Nicol en el hecho de que puede adoptar distintas disposiciones o actitudes ante el ser de los entes; por ejemplo, respecto a la naturaleza cabe actuar en un sentido religioso, estético, científico, etc. (cfr. Nicol 1974, p. 214). Ahora bien, la libertad -en relación dialéctica - se opone a la necesidad y a la vez la supone: se le opone porque la libertad es contingencia intrínseca, toca el fundamento mismo del ser humano en tanto humano, a diferencia de la contingencia extrínseca, que sólo afecta las notas no constitutivas de los otros entes ( $c f r$. Nicol 1977, p. 54); y la supone porque «la libertad sin condiciones, definible en sí misma y por sí misma, sería inoperante. Las condiciones que la limitan son necesarias; pero lo son como condiciones de posibilidad» (ibíd. p. 47). En cuanto al azar, «surge en la existencia humana como lo inesperado, lo que sobreviene bruscamente y sin anuncio previo» (ibíd.p. 55). Mientras que la libertad y la necesidad, enlazadas dialécticamente, constituyen la acción del hombre, el azar se particulariza por

4 Para la concepción de la filosofía como ciencia, y ciencia primera, vid. Nicol 1998, pp. 36-44); González, J. 2009; y González, Rush 2007.

5 «Vocaciones» en sentido estricto, sólo las hay en la «praxis impráctica» (cfr. Nicol 1972, p. 121), aunque en sentido lato también la «praxis práctica» tiene sus «vocaciones», es decir, ocupaciones, profesiones, preferencias sistemáticas por una disposición ante los entes (cfr. Nicol 1997, pp. 48-49). 
su carácter adventicio (exterioridad al ser del hombre) y su imprevisibilidad ( $c f r$. ibíd. p. 30, n.2, y pp. 54-56). ${ }^{6}$

En este marco de ideas es que Nicol efectúa una lectura de la situación del hombre en nuestra época. Se trata del tema de la «razón de fuerza mayor».

En El porvenir de la filosofía (1972), Nicol interpreta diversos fenómenos históricos en el sentido de que la sociedad contemporánea está asistiendo al nacimiento de una nueva forma de racionalidad, distinta a la natural (cuya temporalidad tiene como factores a la necesidad y al azar) y a la humana (en la que la historicidad agrega a los factores anteriores la libertad); esa nueva forma de racionalidad es la «razón de fuerza mayor». Todo comienza con la explosión demográfica, pero a ésta se añaden otros factores: la escasez de recursos, el aumento del costo de la producción industrial, la impotencia de la tecnología para compensar tal situación:

La población rebasa las disponibilidades industriales y alimenticias. El colapso progresivo del equipo industrial produce el colapso de los servicios, de la agricultura y de la beneficencia pública, sin que disminuya el índice de la contaminación de las reservas biológicas primarias. Nos informan en este lenguaje que toda proyección que pueda hacerse ahora del crecimiento, termina en un descenso brusco de todos los índices de ese crecimiento. El fin es próximo. (Nicol 1972, p. 170; cfr. ibíd.pp. 62-63.)

En el planteamiento de Nicol, el proceso se desarrolla a nivel global y su solución no depende de un mayor esfuerzo o una mayor eficacia, sino «de que el hombre conserve la iniciativa, incluso cuando las medidas saludables implican una coerción para la mayoría, o bien que sea nada más que el transmisor o ejecutor de una coerción más radical» (cfr. Nicol 1970, p. 58). En otras palabras: o para salvar la vida propiamente humana del hombre se pone en riesgo la pervivencia del mismo sobre la tierra, o en aras de su sobrevivencia se sacrifica la vida propiamente humana. Se trata de una «progresiva unificación de los criterios vitales» (ibíd. p. 31), que subordina el conjunto de esos criterios al de la supervivencia en su sentido más estricto.

Esta interpretación de fenómenos contemporáneos se complementa con la elaboración del concepto de razón de fuerza mayor. Escribe Nicol: «la fuerza instintiva de la especie, al recuperar la directiva reduciendo a uno solo todos los variados fines de la acción histórica, tiene que recurrir a los mismos instrumentos y procedimientos creados por la praxis histórica»; anteriormente la cultura «se apoyaba en la naturaleza, y la superaba sin corromperla ni destruirla», mientras que «ahora es la naturaleza humana la que, para recuperarse, ha de someter a la

6 Para el tema de la racionalidad y la historia respecto a la concepción del hombre en la filosofía de Nicol, vid. Domínguez 1990. 
cultura» (ibíd.p. 63). La nueva racionalidad no corresponde a la natural, pues se sirve de la cultura, pero tampoco corresponde a la humana, ya que sirve a una finalidad propiamente natural y no humana: es la razón de fuerza mayor. ${ }^{7}$

Es muy importante remarcar que, así planteada por Nicol, la razón de fuerza mayor no se refiere a un circunstancial predominio de la «praxis práctica» sobre la «práxis impráctica». Aunque menos libre que ésta (dado que una da por supuestos los fines, mientras que la otra - en su forma filosófica - no sólo hace conscientes los mismos sino que llega a problematizarlos radicalmente), la «praxis práctica» no deja de ser libre: «El salto de género, de la naturaleza a la historia, se da con el trabajo», pues «si fuese una actividad natural, el trabajo sería uniforme, en todos y cada uno», pero «es actividad histórica porque es variable» (Nicol 1972, p. 80). La crisis del hombre en la sociedad actual -conforme a la descripción de Nicol- posee mayor radicalidad que cualquier crisis del sistema económico, debido a que en tal descripción el sistema económico forma parte de la «praxis práctica» -independientemente de que dentro de ésta se le asigne o no se le asigne un lugar básico-, y lo que plantea este filósofo es que la crisis afecta a la praxis humana en su conjunto (tanto la «impráctica» como la «práctica»). La separación que en el análisis de Nicol nota Sánchez Vázquez entre la crisis del hombre y «la crisis del sistema económico y social en que se inserta» (Sánchez Vázquez 1997, 193), desde la estructura conceptual del mismo Nicol ha de ser entendida por tanto en el sentido de que la economía no juega un papel determinante en la crisis que opera la razón de fuerza mayor en el hombre y en el ámbito de lo humano.

Interpretada la crítica de Sánchez Vázquez como lo hicimos en la sección anterior, y tomando en cuenta las ideas de Nicol que recuperamos en la presente sección, cabe pensar que el contraste entre estos filósofos se centra en el lugar que cada uno de ellos asigna a la economía en el horizonte de la vida humana, de la sociedad y la historia. De acuerdo con tal lectura, Sánchez Vázquez defendería el carácter básico y determinante de la economía, mientras que Nicol no reconocería ese carácter. En la siguiente sección examinamos esta aparente discordancia.

\section{SÁNCHEZ VÁZQUeZ y Nicol SOBRE LA RACIONALIDAD DE LA HISTORIA: ECONOMÍA Y LIBERTAD}

El contraste entre Nicol y Sánchez Vázquez no implica, por una parte, que el primero niegue la determinación del factor económico sobre la vida del hombre (si entendemos esa determinación al modo de Sánchez Vázquez), ni,

7 Para las relaciones entre el tema de la razón de fuerza mayor en la obra de Nicol y la Teoría Crítica, vid. Sánchez Cuervo (2009). 
por otra parte, que el segundo lleve tal determinación hasta el punto de ahogar la autonomía de las otras estructuras sociales.

Nicol escribe: «El hecho mismo de una causalidad económica es indudable; lo que es dudoso es su alcance» (Nicol 1965, p. 256). La causalidad económica es tan operante como la natural. Como ya señalamos, en la metafísica de Nicol la racionalidad de la historia se explica por tres factores, la necesidad, la libertad y el azar; pues bien, la necesidad se puede entender en dos sentidos: «La necesidad debe entenderse primariamente como la efectividad real de la causa, como vínculo de la relación entre causa y efecto», y «en términos más especiales, entendemos también por necesidad la constitución de un sistema de causas que, siendo ajenas al designio de los hombres, ejercen sin embargo en su vida una influencia insoslayable» (ibíd. p. 243). En el primer sentido, tanto el azar como la libertad son una necesidad en la vida del hombre: el hombre, en tanto hombre, es constitutivamente un ser libre, pero también ha de contar en su vida con un factor de azar en general, aunque por definición no le sea dado prever el contenido de ese azar. En el segundo sentido (por el cual la necesidad se opone al azar y a la libertad), la naturaleza y la economía, en tanto sistemas de causas, son ajenas al designio de los hombres; ajenas al menos mientras el hombre no toma conciencia de esas causas y no asume el control sobre ellas. Es un hecho que el hombre puede conocer y utilizar para su beneficio las leyes de la naturaleza y de la economía; pero también es un hecho que para dominar esas leyes, ha de obedecerlas. ${ }^{8}$ Lo que Nicol sostiene, en definitiva, es que «ni la causalidad natural ni la causalidad económica son necesarias en el sentido de unívocamente determinantes de las formas de existencia humana y del proceso histórico» (ibíd. p. 244).

De forma convergente, Sánchez Vázquez reconoce que las estructuras que dependen del sistema económico-social poseen «una cierta autonomía» (FP, p. 421). Para ilustrar el sentido de tal autonomía, veamos cómo analiza Sánchez Vázquez la relación entre la teoría y la praxis. ${ }^{9}$ A la teoría la entiende como una actividad humana distinta de la praxis, que comprende tanto la producción de fines como de conocimientos (cfr. ibíd.pp. 279-282). Pues bien, en este sentido, «la práctica mantiene su primacía con respecto a la teoría, sin que esta primacía disuelva la teoría en la práctica ni la práctica en la teoría» (ibíd. p. 313). La práctica es fundamento, criterio de verdad y fin de la teoría. En primer lugar, la práctica es fundamento de la teoría porque «sobre la base de los conocimientos

8 Nicol reflexiona sobre el significado de Bacon en el contexto de la crisis de nuestro tiempo, en Nicol 1980, pp. 46-61.

9 También puede servir de ilustración la autonomía del arte respecto a las estructuras económico-sociales (especialmente en lo tocante al caso del realismo socialista). Para este tema, vid. Cepedello 2013. 
empíricos acumulados durante milenios surgen los gérmenes de un conocimiento teórico y se forman las categorías lógicas para ello», considerando que «esta fase inicial del conocimiento se halla vinculada a la necesidad de construir los primeros instrumentos de trabajo, así como a las exigencias de las primitivas prácticas productivas»; pero también en razón de que aún ahora la relación entre el hombre y el mundo natural, mediante la producción material, «plantea exigencias que contribuyen a ampliar tanto el horizonte de los problemas como de las soluciones» (ibíd.p. 292; cfr. ibíd. 291-293). En segundo lugar, la práctica es fin de la teoría porque ésta «responde no sólo a una actividad práctica que se da ya efectivamente, y que con sus exigencias impulsa su desarrollo, sino también de una práctica que no existe aún, o que sólo se da en forma embrionaria»; es decir, la teoría también responde a «la necesidad de nuevas actividades prácticas transformadoras», para las cuales el hombre «carece aún del necesario instrumental teórico» (ibíd. p. 308; cfr. ibíd.pp. 307-309). ) Y en tercer lugar, la práctica es en última instancia criterio de verdad de la teoría porque, a diferencia del pragmatismo - el cual «aspira a probar lo verdadero como lo útil» (ibíd. p. 289), entendiendo lo útil en tanto éxito o eficacia de la acción individual-, el marxismo «trata de probar lo verdadero como reproducción espiritual de la realidad», en el sentido de que «la práctica social revela la correspondencia o no de un pensamiento con la realidad» (ibíd. p. 290; cfr. ibíd. pp. 286-291, 312). Por estas tres razones, la práctica tiene primacía sobre la teoría. Ahora bien, la relativa autonomía de ésta respecto de aquella es condición necesaria para que la teoría sirva a la práctica, pues implica que la teoría no se limite a seguir a la práctica, y que se adelante a ella: «el conocimiento de cierta legalidad del objeto permite, en efecto, prever determinadas tendencias de su desarrollo y, de este modo, anticipar con un modelo ideal una fase de su desenvolvimiento no alcanzada aún» (ibíd.p. 313); el modelo ideal, para propiciar una práctica inexistente, ha de adelantarse idealmente a ella. En este sentido, Sánchez Vázquez no afirma una determinación unívoca de las estructuras económicas sobre las otras estructuras de la sociedad.

Regresando a Nicol, ya indicada la relación que rechaza entre economía y sociedad, precisemos qué relación afirma. En La reforma de la filosofía, este filósofo estudia la génesis y los caracteres básicos de la praxis (1980, pp. 114124). Ahí plantea, al igual que Sánchez Vázquez, que «el hombre es el ser de la praxis» (ibid. p. 115). Pero el concepto de praxis posee diferentes notas en un filósofo y en otro. Para Sánchez Vázquez la praxis es una forma específica de actividad humana que tiene como distintivo su materialidad (cfr. FP, 263-271): ${ }^{10}$

10 Sánchez Vázquez considera que el materialismo de Marx (en su aspecto gnoseológico) supera el materialismo tradicional a partir de las Tesis sobre Feuerbach. El materialismo tradicional, conforme a Sánchez Vázquez, no reconoce en el objeto un producto de la actividad del 
en cambio, cuando Nicol habla de la praxis se refiere a la actividad humana en general ( $c f r$. Nicol 1980, pp. 114-124). Conforme a este último filósofo, la praxis evoluciona históricamente, de manera que a través del tiempo adquiere caracteres que pasan a ser necesarios para ella; por eso afirma que «la praxis fue generada por la praxis» (ibíd. p. 116), entendiendo la praxis en dos sentidos: como «praxis práctica» y como «praxis impráctica», de tal modo que la primera genera a la segunda: «el hombre era ya un ser práctico, y la praxis tenía incluso una historia prolongada y rica, antes de que adquiriese los caracteres definitivos que, por esto mismo, deben incluirse en la definición» (íd.). La «praxis práctica» es necesaria para la subsistencia en un sentido biológico, natural, mientras que la «praxis impráctica» es necesaria en un sentido completamente distinto, en tanto permite al hombre una existencia más libre (cfr. ibíd.p. 119): en la «praxis práctica» la libertad se hace presente cuando el hombre varía los medios de satisfacer sus necesidades, mientras que en la «praxis impráctica» la libertad ya no se refiere sólo a los medios, incide en la creación y variación de las necesidades mismas (cfr. ibíd.pp. 253-262). El hombre descubre históricamente disposiciones ante el ser que, una vez descubiertas y cultivadas de forma creativa, pasan a formar parte del ser constitutivo del hombre, es decir, se incorporan a las potencialidades inherentes al ser humano; así la religión, el arte y la ciencia: «la perfección adquirida una primera vez queda como posibilidad abierta para todos en el porvenir» (ibíd. p. 120). La ciencia, en tanto filosofía, revela al hombre «la problematicidad esencial de la praxis», es decir, «el hecho de que ninguno de sus fines prácticos puede concebirse como fin final» (ibíd. p. 118). $\mathrm{La}$ «praxis práctica» no tiene sentido en sí misma; su sentido, históricamente variable, depende de un «para qué» que es exterior a ella en dos sentidos: en primer lugar ese «para qué», como respuesta al interrogante por el sentido de la «praxis práctica», emerge en el ámbito de una reflexión que no pertenece a la «praxis práctica»; en segundo lugar, ese «para qué» subordina la «praxis práctica», como medio, al cumplimiento de una meta que no se sitúa en el orden de la práctica, un fin no intermedio sino final: «por obra de la filosofía, el hombre se convierte en la finalidad de su praxis» (ibíd. p. 120). La «praxis práctica», en la reflexión filosófica, se muestra como un instrumento para que el hombre produzca históricamente su propio ser. Tal énfasis en la idea de que la realización del hombre en tanto hombre está más allá de la «praxis práctica», podría llegar a entenderse - como indicamos al final de la sección anterioren el sentido de que esta realización, como ejercicio de la libertad, no se sujeta al sistema de causas de la naturaleza o la economía. La tesis de Nicol, muy al

sujeto; en cambio, «Marx ha puesto la práctica como fundamento del conocimiento al rechazar la posibilidad de conocer al margen de la actividad práctica del hombre» (FP, p. 171). Para este tema, vid. Gandler 2013. 
contrario, es que naturaleza y economía operan siempre en el ser del hombre, sólo que en vez de ahogar a la libertad la hacen - dialécticamente- posible. La «praxis práctica» es un medio para la realización del hombre en tanto hombre; pero no un medio prescindible: medio en el sentido de condición necesaria. La realización humana, aunque no es posible sólo con la «praxis práctica», tampoco lo es sin ella: «no hay liberación de la necesidad, pero sí hay una superación», pues «lo que pudiera llamarse liberación de lo forzoso consiste en la producción, por medios naturales o físicos y con el concurso de las causas necesarias, de algo que la naturaleza no depara por sí sola» (ibíd. p. 123).

Si para Nicol la «praxis impráctica» es el lugar y el medio donde y por el cual el hombre transforma su propio ser y supera la naturaleza, para Sánchez Vázquez ese lugar y ese medio corresponden a una forma de lo que Nicol concibe como «praxis práctica»: la producción, la praxis como actividad humana material (cfr. FP, p. 149). El hombre, de acuerdo con la interpretación que Sánchez Vázquez hace de Marx, ${ }^{11}$ produce para satisfacer necesidades, como el animal; pero las necesidades del hombre no son naturales sino «específicamente humanas»: «ello quiere decir que la necesidad propiamente humana tiene que ser inventada o creada» (ibíd.p. 150). Ahora bien, «en la medida en que el hombre crea sus propias necesidades se crea o produce a sí mismo» (id.), de manera que «el trabajo - la producción - es lo que eleva al hombre sobre la naturaleza exterior y sobre su propia naturaleza, y en esa superación de su ser natural consiste propiamente su autoproducción» (ibíd.p. 151). Esto nos aclara la concepción de Sánchez Vázquez respecto al lugar de la economía en la sociedad. Pues, por una parte, la producción material, económica, «no es sólo producción de un mundo de objetos, de bienes útiles» sino «también producción de relaciones sociales y condición necesaria de todo tipo de producción» (ibíd. p. 421), ${ }^{12}$ pero no en el sentido de un «condicionamiento unidimensional — de causa a efecto-», pues «si bien lo no económico se explica en última instancia por lo económico [...], lo económico, a su vez, aun siendo determinante, no puede explicarse de por sí, y en cuanto que es un elemento de una totalidad, tiene que ser explicado, a su vez, por lo no económico» (ibíd. pp. 421-422). Las estructuras económicas son la base y el factor determinante en la sociedad, considerada como una totalidad, debido a que han de ser entendidas como condición necesaria de todo tipo de producción, pero esas estructuras económicas son explicadas por las no económicas debido a que el hombre no produce para satisfacer necesidades naturales sino que inventa unas necesidades propiamente humanas: aunque la economía posee un carácter básico y determinante, su sentido no reposa en ella misma. Las estructuras no económicas, como la ciencia, aunque tienen

11 Sánchez Vázquez se refiere a los Manuscritos económico-filosóficos de 1844.

12 Cursivas nuestras. 
como condición necesaria a la economía, además de ser autónomas respecto a ésta, le confieren sentido. El para qué de la economía hay que buscarlo en esas necesidades propiamente humanas que el hombre inventa en un proceso sin término, o lo que es lo mismo, en el ser del hombre, en tanto tal ser es producto de la actividad del hombre mismo. ${ }^{13}$

Como vemos, en lo relativo al lugar de la economía en la sociedad y la historia es correcto hablar de un contraste entre Nicol y Sánchez Vázquez, pero un contraste que no significa una discrepancia de fondo sino una diferencia de énfasis. Ambos filósofos niegan una determinación económica fuerte (i.e. que lo económico sea causa necesaria y suficiente de lo no económico); y ambos reconocen en cambio, en primer lugar, que junto con la necesidad económica hay otras causas necesarias, como la necesidad natural y la libertad (hemos visto que Nicol agrega explícitamente el azar), y en segundo lugar, que estas estructuras (la ciencia y el arte, por ejemplo), además de ser autónomas, explican a su vez a la economía, le dan un para qué, un sentido, el cual se refiere al ser del hombre como obra de sí mismo. La diferencia de énfasis consiste en que Sánchez Vázquez remarca la necesidad de una producción material para la autocreación del hombre, mientras que Nicol pone de relieve la necesidad de una «praxis impráctica» (es decir, de la actividad no práctica en general, la cual en el esquema conceptual de este filósofo excluye a la producción material).

\section{CONCLUSIONES}

¿A qué responde la diferencia de énfasis entre Nicol y Sánchez Vázquez, si hay una convergencia de fondo? No olvidemos que el servicio de la teoría a la sociedad radica, para este filósofo marxista, en su alineamiento con una praxis revolucionaria (cfr. FP, pp. 300-307); mientras que para la metafísica de Nicol ese servicio hay que buscarlo en una depuración de las motivaciones que mueven al hombre a actuar (cfr. Nicol 1982, pp. 140-150). Sánchez Vázquez otorga primacía al mejoramiento de la vida del hombre mediante la transformación de su base material; de ahí que la divisa de su filosofía sea la undécima tesis de Marx sobre Feuerbach: «Los filósofos se han limitado a interpretar el mundo de distintos modos; de lo que se trata es de transformarlo» (FP, p. 179). Nicol está seguro de que aun sin esa transformación la teoría - así como las otras vocaciones

13 Sánchez Vázquez, al tocar el tema de la racionalidad de la historia, evita suprimir o disminuir el factor objetivo de dicha racionalidad en aras de su factor subjetivo, así como el subjetivo en aras del objetivo. Objetivamente, los hombres han de obedecer ciertas leyes que rigen al sistema económico-social en el que viven, leyes de las que dependen las otras estructuras de la sociedad (ciencia, arte, etc.); pero los hombres no por ello dejan de ser entes de conciencia y voluntad, entes libres, que mediante su decisión y acción pueden transformar ese sistema. Vid. FP, pp. 442-443, y Sánchez Vázquez 2003b pp. 387-403. 
libres - ya opera un mejoramiento efectivo del ser del hombre: "pensar el mundo es transformarlo" (Nicol 1978, p. 19). En los dos casos se trata del hombre que se libera y de una teoría autónoma respecto a su base económica; la diferencia nos remite a la cuestión de si es o no es posible una liberación del hombre en tanto hombre sin una transformación de las estructuras fundamentales del sistema económico en el que vivimos. La amenaza que describe Nicol, la emergencia de la razón de fuerza mayor, es, en los términos de este filósofo, más radical que cualquier situación de injusticia económica o política, pues no se refiere a la opresión o exclusión de unos hombres por otros hombres sino a la extinción del hombre en tanto tal. En cambio, el mal a cuyo remedio consagra Sánchez Vázquez su pensamiento corresponde precisamente a esa injusticia, de la cual percibe que se derivan los problemas que amenazan la supervivencia del hombre sobre la tierra; por ejemplo, la posibilidad «de un holocausto nuclear, de un cataclismo ecológico o de la supeditación de los logros genéticos al mercado», posibilidad en la cual hay que ver, de acuerdo con este filósofo, un capitalismo que en su fase globalizadora coloca «el desarrollo científico y tecnológico bajo el signo del lucro y la ganancia» (Sánchez Vázquez 2007, p. 118).

El «antropologismo», la «carga especulativa» de la metafísica de Nicol, a los ojos de Sánchez Vázquez, hay que ubicarla en la importancia que otorga a una forma no económica de deshumanización. Desde la óptica de Nicol, en cambio, la deshumanización ética, política, económica, que coloca Sánchez Vázquez en primer plano, es derivada y soslaya lo verdaderamente radical, la existencia del hombre en tanto tal. Para nosotros, lectores de ambos, los dos aspectos son igualmente relevantes. Sabemos que una transformación económica y política puede traer consigo nuevas formas de deshumanización; pero también estamos conscientes de que el ejercicio vocacional de unos hombres puede darse a costa de excluir a otros hombres de ese mismo ejercicio, con base en unas determinadas estructuras económico-sociales de opresión. Sea que estemos o no estemos de acuerdo con la elaboración teórica que hace Nicol del concepto de razón de fuerza mayor, coincidimos con él en la necesidad de humanizar al hombre mediante formas de vida que cultivan lo más humano que hay en él y no sólo el aspecto práctico o económico de su vida; y sea que concordemos o no concordemos con Sánchez Vázquez en la dirección marxista de la transformación económico-social que requiere nuestra sociedad, no podemos sino convenir con él en la urgencia de ocuparnos de las condiciones materiales, prácticas, económicas, que impiden una vida más humana para el hombre. ${ }^{14}$

14 Es importante observar que el planteamiento de Sánchez Vázquez respecto a dicha transformación económico-social asimila para el marxismo la experiencia del llamado «socialismo real» en el siglo XX. Vid. Sánchez Vázquez 1999, pp. 231-246 y 247-2555. 
Una metafísica en plan científico y un marxismo crítico no se excluyen por necesidad. Específicamente, en la filosofía de la praxis de Adolfo Sánchez Vázquez y en la metafísica de la expresión de Eduardo Nicol encontramos vías abiertas al diálogo y la comprensión, y sobre todo, semillas para una recíproca fecundación.

\section{REFERENCIAS}

CEPEDELLO, J. 2013: «Praxis, ideología y filosofía política en la teoría estética de Adolfo Sánchez Vázquez.» Fragmentos de filosofía, 11: 143-160.

DOMÍNGUEZ, U. 1990: «Ontología e historia», en González, J. y Sagols, L. 1990: El ser y la expresión. Homenaje a Eduardo Nicol. México: UNAM, pp. 123-131.

FP. vid. Sánchez Vázquez, 2003a.

GANDLER, S. 2014: «Teoría crítica y materialismo hoy: Alfred Schmidt y la filosofía marxista en México.» Utopía y praxis latinoamericana, XVIII (61): pp. 25-36.

GARCÍA MACHADO, X. 2009: «Senderos de la filosofía de la praxis como reconstrucción de la filosofía del marxismo», en Velasco Gómez, A. (coord.) Vida y obra. Homenaje a Adolfo Sánchez Vázquez. México: UNAM, pp. 225-243.

GONZÁLEZ, J. 2009: «La ciencia-filosofía en Eduardo Nicol.» Theoría, 19: pp. 11-24.

GONZÁLEZ, Roberto 2014: «Metafísica y contradiscurso del método: Hacia una nueva concepción del ser a partir de la óptica de Eduardo Nicol.» Revista de filosofía, XXXIX (1): 29-45.

GONZÁLEZ, Rush 2007: «Estructura, historia y unidad de la ciencia a partir de la óptica de Eduardo Nicol.» CIENCIA ergo sum, XIV (2): pp. 208-216.

NICOL, Eduardo 1963: Psicología de las situaciones vitales. 2a ed. México: FCE.

, 1965: Los principios de la ciencia. México: FCE.

___ 1972: El porvenir de la filosofía. México: FCE.

___ 1974: Metafísica de la expresión. México: FCE.

___ 1977: La idea del hombre. México: FCE.

___ 1978: La primera teoría de la praxis. México: UNAM.

___ 1980: La reforma de la filosofía. México: FCE.

—_— 1982: Crítica de la razón simbólica. México: FCE.

___ 1997: La vocación humana. México: CONACULTA.

___ 1998: El problema de la filosofía hispánica. México: FCE. 
SÁNCHEZ CUERVO, A. 2009: «Eduardo Nicol y la crítica de la razón instrumental», en Horneffer, R. 2009: Eduardo Nicol (1907-2007). Homenaje. México: UNAM, pp. 121-137.

SÁNCHEZ VÁZQUEZ, Adolfo 1997: Filosofía y circunstancias. México: UNAM; Barcelona: Anthropos

_, 1999: Entre la realidad y la utopía. Ensayos sobre política, moral y socialismo. México: FCE/UNAM.

___ 2003a: Filosofía de la praxis. México: Siglo XXI.

___ 2003b: A tiempo y destiempo. Antología de ensayos. México: FCE. , 2007: Ética y política. México: FCE/UNAM.

VARGAS LOZANO, G. 1995: «Los sentidos de la filosofía de la praxis», en En torno a la obra de Adolfo Sánchez Vázquez, del mismo (ed.). México: UNAM.

Iver A. Beltrán G. es Doctor en Filosofía por la Universidad Nacional Autónoma de México (UNAM) y actualmente se desempeña como Profesor Investigador en la Universidad de Chalcatongo (Oaxaca, México).

Lineas de investigación:

Antropología filosófica, Filosofía de la cultura, Historia de la Filosofía en México durante el siglo XX.

Publicaciones recientes:

(2017) «Diálogo, comunidad, historia. La teoría de las vocaciones en la metafísica de Eduardo Nicol.» en Comprendre. Revista catalana de filosofia, vol. 19, núm. 1, pp. 19-37.

(2017) «Dialéctica del reconocimiento. Universalidad y particularidad en la filosofía de la historia de Leopoldo Zea» en THÉMATA. Revista de Filosofía, núm. 55, pp. 249-266.

Correo electrónico:

iivehr@hotmail.com 